\title{
Испарение кластера капель при движении в высокотемпературной газовой среде
}

\author{
() В.А. Архипов, С.А. Басалаев , А.И. Коноваленко, К.Г. Перфильева \\ Национальный исследовательский Томский государственный университет, Томск, Россия \\ ๑ E-mail: tarm@niipmm.tsu.ru
}

Поступило в Редакцию 20 марта 2020 г.

В окончательной редакции 26 марта 2020 г.

Принято к публикации 26 марта 2020 г.

\begin{abstract}
Предложен новый способ определения скорости испарения компактной группы (кластера) капель при гравитационном осаждении в высокотемпературной газовой среде. Представлены результаты экспериментального исследования скорости испарения кластера капель дистиллированной воды радиусом $0.77 \mathrm{~mm}$ в диапазоне температур 650-800 К. Выявлено существенное снижение скорости испарения с уменьшением расстояния между каплями.
\end{abstract}

Ключевые слова: кластер капель, расстояния между каплями, высокотемпературная газовая среда, скорость испарения.

DOI: 10.21883/PJTF.2020.12.49527.18300

Основной объем информации по методам и результатам экспериментального исследования процессов испарения относится к одиночным каплям (см., например, обзор в [1]). В большинстве практических приложений (в частности, при анализе эффективности тушения пожаров тонкораспыленной водой [2]) реализуется процесс испарения группы капель. При этом наблюдается эффект влияния соседних капель на скорость и полноту испарения. Теоретические оценки этого эффекта приведены для двух модельных „капель“ в виде прямоугольников, вытянутых в направлении их движения [1].

Экспериментальному исследованию закономерностей испарения группы капель посвящены единичные публикации $[1,3]$. В частности, в [1] обобщены результаты исследований процесса испарения полидисперсного потока капель радиусом $0.1-0.3 \mathrm{~mm}$, получаемых с помощью диспергирования дистиллированной воды распылительной форсункой. Нагрев капель осуществлялся продуктами сгорания типичного горючего вещества. Концентрация и размер капель измерялись оптическими методами. Для оценки полноты испарения капель в высокотемпературной газовой области использовался безразмерный параметр

$$
\delta R=\frac{R_{0}-R_{k}}{R_{0}} \cdot 100 \%,
$$

где $R_{0}$ и $R_{k}$ - радиусы капли на входе и выходе из области нагрева.

В работе [4] рассмотрены закономерности движения, коагуляции и испарения в высокотемпературной среде нескольких последовательно падающих капель воды.

Целью настоящей работы является экспериментальное исследование особенностей испарения кластера монодисперсных капель дистиллированной воды диаметром $0.77 \mathrm{~mm}$, движущихся в высокотемпературной газовой среде, в зависимости от температуры газовой среды и среднего расстояния между каплями. Методика измерения принципиально отличается от известных $[1,3,4]$ осреднением скорости испарения по большому количеству капель $\left(\sim 10^{3}\right)$, что повышает точность полученных результатов.

Схема экспериментальной установки [5] приведена на рис. 1. Полый цилиндрический нагреватель выполнен из керамической трубы 1 диаметром $12 \mathrm{~cm}$ и высотой $L=1 \mathrm{~m}$, на внутренней поверхности которой установлены проволочные нихромовые спирали 2, соединенные с источником напряжения 3. Мерная емкость 4 с набором капилляров одинакового диаметра 5 располагается над верхним срезом трубы 1. В качестве мерной емкости использован цилиндр из фторопласта, в торце которого установлен набор из девяти медицинских игл с внешним диаметром $0.8 \mathrm{~mm}$. В мерную емкость 4 помещена исследуемая жидкость 6 . Внутренняя полость мерной емкости 4 соединена с воздушным микрокомпрессором 7 через электропневмоклапан 8 , который управляется низкочастотным генератором напряжения 9. Скоростные видеокамеры 10 установлены на входе и на выходе трубы 1, приемная емкость 11 установлена на выходе трубы 1. Температура газа в зоне нагрева трубы 1 контролируется съемными термопарами 12, расположенными по ее оси. Сигналы от термопар 12 через усилитель 13 поступают на осциллограф 14.

При проведении эксперимента внутренняя полость трубы 1 прогревается до заданной температуры в диапазоне 600-850 K, контролируемой термопарами 12. После выравнивания температуры в полости трубы 1 термопары 12 удаляются из зоны нагрева. В мерную емкость 4 заливается исследуемая жидкость 6. При подаче импульсов напряжения от генератора 9 на электропневмоклапан 8 в полости мерной емкости 4 создаются импульсы давления, которые приводят к одновременному отрыву капель от срезов капилляров 5. При этом 


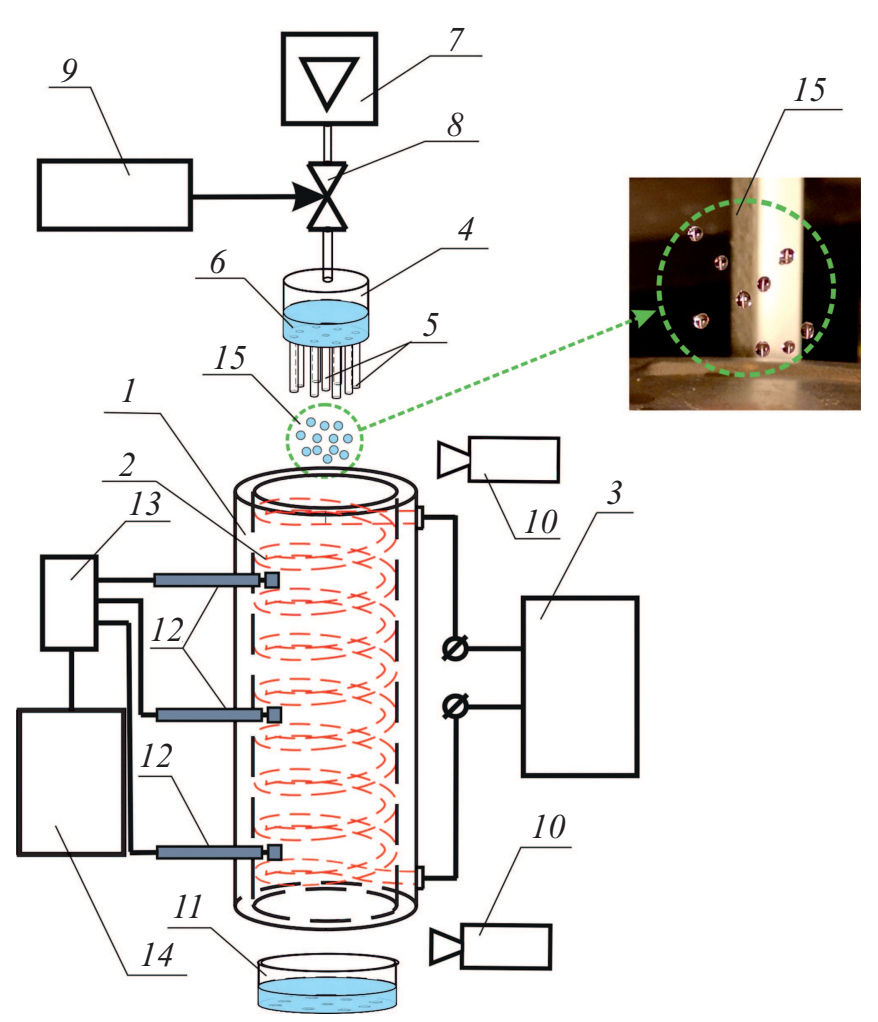

Рис. 1. Схема экспериментальной установки. Пояснения в тексте.

образуется компактный кластер монодисперсных капель 15. При многократной подаче импульсов давления в нагреватель последовательно поступают идентичные группы капель.

Скорость испарения капли определяется уравнением [6]:

$$
W=\rho_{p} \frac{\Delta R}{\Delta t},
$$

где $\rho_{p}$ - плотность жидкости; $\Delta R=R_{0}-R_{k}$ - изменение радиуса капли за время нагрева $\Delta t$.

Предположим, что за время измерения в нагреватель поступило $N_{0}$ капель с суммарной массой $m_{0}=4 N_{0} \rho_{p} \pi R_{0}^{3} / 3$, а в приемную емкость $-N_{k}$ капель с суммарной массой $m_{k}=4 N_{k} \rho_{p} \pi R_{k}^{3} / 3$. При $N_{0}=N_{k}$ изменение радиуса капли определяется формулой

$$
\Delta R=R_{0}-R_{k}=R_{0}\left(1-\sqrt[3]{\frac{m_{k}}{m_{0}}}\right) .
$$

Для расчета времени нагрева $\Delta t$ рассмотрим уравнение гравитационного осаждения капли [7]:

$$
\rho_{p} V_{0} \frac{d u}{d t}=g V_{0}\left(\rho_{p}-\rho_{g}\right)-C_{D} S_{m} \frac{\rho_{g} u^{2}}{2}
$$

где $V_{0}=4 \pi R_{0}^{3} / 3$ - начальный объем капли, $u-$ скорость движения капли, $t-$ время, $C_{D}-$ коэффициент сопротивления, $S_{m}=\pi R_{0}^{2}-$ площадь миделева сечения капли, $g$ - ускорение свободного падения, $\rho_{g}$ - плотность газа.

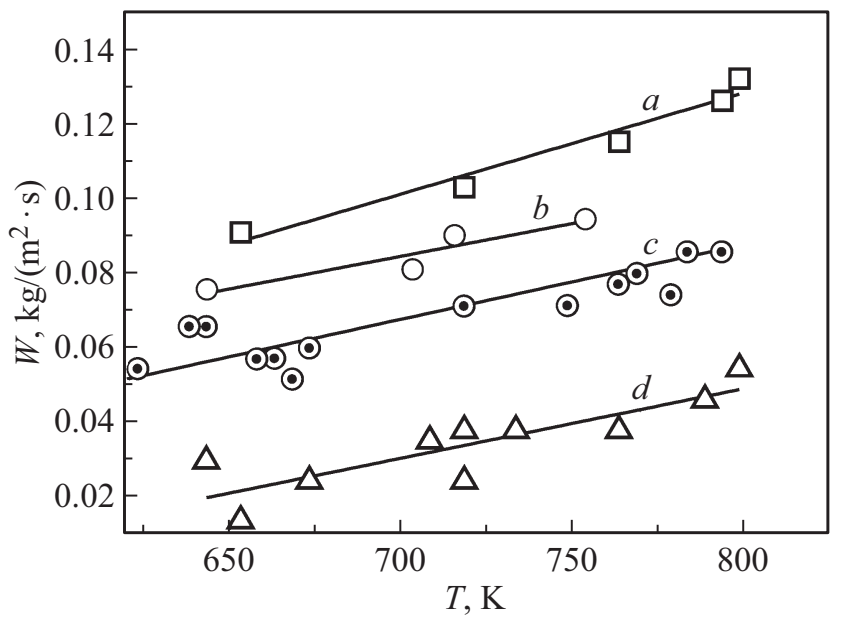

Рис. 2. Зависимость скорости испарения от температуры. $n=1(a), 2(b), 4(c)$ и $9(d)$.

Для расчета скорости капли $u(t)$ представим уравнение (4) в безразмерном виде

$$
\frac{d y}{d \tau}=1-y^{2}
$$

где $y=u / u_{*}-$ безразмерная скорость капли, $\tau=t / t_{*}-$ безразмерное время $\left(t_{*}=u_{*} / g\right)$.

Масштаб скорости $u_{*}$ соответствует скорости стационарного осаждения капли и определяется из уравнения (4) при $d u / d t=0$ :

$$
u_{*}=\sqrt{\frac{2 \rho_{p} g V_{0}}{\rho_{g} C_{D} S_{m}}} .
$$

Для капли жидкости реализуется автомодельный режим осаждения, при котором $C_{D}=\mathrm{const}=0.44$ [8]. При этом из (6) следует

$$
u_{*}=2.46 \sqrt{R_{0} g \rho_{p} / \rho_{g}} .
$$

Аппроксимация решения уравнения (5) с нулевыми начальными условиями $(\tau=0, y=0)$ в диапазоне $\tau \leq 0.75$ имеет вид

$$
y(\tau)=0.93 \tau
$$

Подставляя (7) в уравнение для безразмерного расстояния $\xi=x / x_{*}$, пройденного каплей,

$$
\xi(\tau)=\int_{0}^{\tau} y(\tau) d \tau
$$

и проводя интегрирование, получим (с учетом $\left.x_{*}=u_{*} t_{*}\right)$ формулу для определения $\Delta t$ в размерном виде

$$
\Delta t=1.466 \sqrt{L / g} .
$$




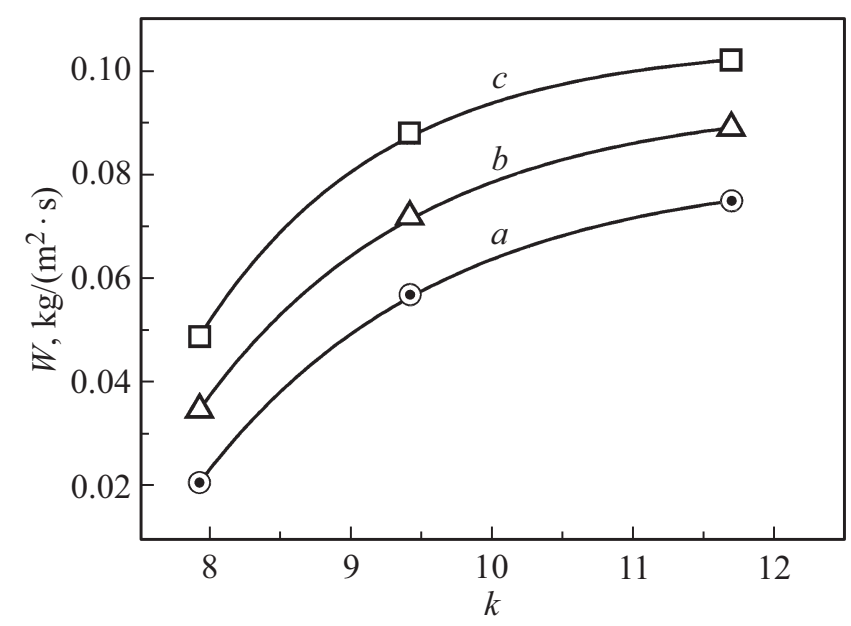

Рис. 3. Зависимость скорости испарения от параметра $k$. $T=650(a), 725(b), 800 \mathrm{~K}(c)$.

Подставляя $\Delta R$ из (3) и $\Delta t$ из (8) в уравнение (2), получим соотношение для определения скорости испарения каждой из капель в кластере

$$
W=0.682 \rho_{p} R_{0} \sqrt{g / L}\left(1-\sqrt[3]{m_{k} / m_{0}}\right) .
$$

Радиус капель $R_{0}$ измерялся по результатам видеосъемки с погрешностью $\sim 4 \%$, значения $m_{0}$ и $m_{k}$ определялись взвешиванием на аналитических весах с погрешностью $\sim 1 \%$. В проведенных экспериментах $m_{0} \sim 20 \mathrm{~g}$, $N_{0} \sim 2 \cdot 10^{3}-8 \cdot 10^{3}$.

На рис. 2 приведены результаты измерений скорости испарения капель дистиллированной воды с начальным радиусом $R_{0}=0.77 \mathrm{~mm}$ в зависимости от температуры окружающей среды и количества капель в кластере $(n=2,4,9)$. В диапазоне температур $T=650-800 \mathrm{~K}$ скорость испарения как одиночной капли, так и кластера капель линейно возрастает с ростом температуры. Количественные данные по скорости испарения одиночной капли (рис. 2, зависимость $a$ ) хорошо согласуются с известными литературными данными [9], полученными в близких условиях проведения эксперимента, для которых реализуется комбинированный механизм теплообмена $(45 \%$ - радиационный тепловой поток от стенок нагревателя, 40\% - конвективный нагрев, $15 \%$ - кондуктивный нагрев).

В проведенной серии экспериментов обнаружено существенное уменьшение скорости испарения с увеличением количества капель в кластере (рис. 2, зависимости $b-d)$. Увеличение количества капель в кластере приводит к увеличению их объемной концентрации $C_{V}$, которая характеризуется безразмерным параметром $k=l / 2 R_{0}$, где $l-$ среднее расстояние между центрами капель в кластере. Для используемой в экспериментах установки (рис. 1) значения этого параметра составляют $k=11.7(n=2), k=9.4(n=4)$ и $k=7.9$ $(n=9)$. На рис. 3 приведены зависимости скорости испарения капель от параметра $k$ для различных значений температуры окружающей среды.
Из приведенных на рис. 3 зависимостей следует, что с увеличением параметра $k$ от 7.9 до 11.7 скорость испарения монотонно возрастает от 0.021 до $0.075 \mathrm{~kg} /\left(\mathrm{m}^{2} \cdot \mathrm{s}\right)$ при $T=650 \mathrm{~K}$, от 0.035 до $0.089 \mathrm{~kg} /\left(\mathrm{m}^{2} \cdot \mathrm{s}\right)$ при $T=725 \mathrm{~K}$, от 0.049 до $0.102 \mathrm{~kg} /\left(\mathrm{m}^{2} \cdot \mathrm{s}\right)$ при $T=800 \mathrm{~K}$. Снижение скорости испарения капель с увеличением их концентрации можно объяснить увеличением концентрации водяных паров в кластере. Аналогичный эффект обнаружен в работе [1], где получено снижение скорости испарения потока капель на $14-18 \%$ с увеличением $C_{V}$ от $2 \cdot 10^{-5}$ до $9 \cdot 10^{-5}$. При большом количестве капель в кластере параметр $k$ связан с их объемной концентрацией соотношением [7]:

$$
k=\sqrt[3]{\frac{\pi}{6 C_{V}}} .
$$

Отметим, что в работе [1] параметр $k$ в соответствии с (10) изменялся от 29.7 до 18.7.

\section{Финансирование работы}

Исследование выполнено за счет гранта Российского научного фонда (проект № 15-19-10014).

\section{Конфликт интересов}

Авторы заявляют, что у них нет конфликта интересов.

\section{Список литературы}

[1] Высокоморная О.В., Кузнецов Г.В., Стрижак П.А. Испарение и трансформация капель и больших массивов жидкости при движении через высокотемпературные газы. Новосибирск: Изд-во СО РАН, 2016. 302 с.

[2] Копылов Н.П., Карпов В.Н., Кузнецов А.Е., Федоткин Д.В., Хасанов И.Р., Сушкина Е.Ю. // Вестн. Томск. гос. ун-та. Математика и механика. 2019. № 59. С. 79-86.

[3] Люлин Ю.В., Кабов О.А. // Письма в ЖТФ. 2013. Т. 39. B. 17. C. $88-94$.

[4] Volkov R.S., Kuznetsov G.V., Legros J.C., Strizhak P.A. // Int. J. Heat Mass Transfer. 2016. V. 95. P. 184-197.

[5] Архипов В.А., Басалаев С.А., Коноваленнко А.И., Золоторев Н.Н., Перфильева К.Г., Антонникова А.А. Способ определения скорости испарения группы капель. Заявка № 2019139349 на патент РФ. МПК G01N 21/00. Заявл. 02.12.2019.

[6] Терехов В.И., Пахомов М.А. Тепломассоперенос и гидродинамика в газокапельных потоках. Новосибирск: Изд-во НГТУ, 2008. $284 \mathrm{c}$.

[7] Архипов В.А., Васенин И.М., Усанина А.С., Шрагер Г.Р. Динамическое взаимодействие частиц дисперсной фазы в гетерогенных потоках. Томск: Изд. Дом Томск. гос. ун-та, 2019. $328 \mathrm{c}$.

[8] Нигматулин Р.И. Движение многофазных сред. М.: Наука, 1987. Ч. I. $464 \mathrm{c}$.

[9] Войтков И.С., Волков Р.С., Кузнецов Г.В., Стрижак П.А. // ЖТФ. 2017. Т. 87. В. 12. С. 1911-1914. 